\title{
Analysis on the Practice and Experience of the FIVE AND THREE SYSTEM Construction of State Grid
}

\author{
Fu-You JIANG ${ }^{a, *}$ and Jian ZHU ${ }^{b}$ \\ State Grid Sichuan Electric Power Company, CHINA \\ a17303166@qq.com, b18228087288@139.com \\ ${ }^{*}$ Corresponding author
} Keywords: State Grid, Five Intensive Configurate and Three Big Business System, Group
Operation.

\begin{abstract}
In face of the fundamental problem about how to change from traditional state-owned enterprises to modern enterprises, the State Grid Corporation continues to deepen understanding in innovative practice, constantly breaks the shackles of the traditional management thinking of the power grid enterprises, and promote the construction of FIVE AND THREE SYSTEM which has the main feature of the core business professional, human resource intensive, organizational structure flat, and gradually explore the general rule of development and management of power grid. The construction of FIVE AND THREE SYSTEM in the State Grid Corporation has important implications for other large state-owned enterprises to promote group operation.
\end{abstract}

\section{State Grid Five and Three System Construction Situation}

FIVE AND THREE SYSTEM construction is an all-round, in-depth, fundamental and significant management transform in State Grid's reforming and developing process. In accordance with the overall structure "Two-tier legal representative,three-tier management", taking "Three Intensification"(Human, Capital and Material Intensification) resource intensive configuration system, "Five" business (planning, construction, operation, maintenance and marketing) professional operating system, supporting the security system as the core, the system transforms the organization structure, innovates management model, optimizes business process,deepens the intensive management of core resources of human, capital and material, promote the construction of "Five Big" system and related mechanisms, strengthens State Grid headquarters, optimizes provincial companies, fulfills municipal companies, builds State Grid into a modern power grid enterprise with centralized and efficient management, resource-intensive sharing, business integration and flat organization structure.

\section{End of 2014}

\begin{tabular}{|c|c|c|}
\hline $\begin{array}{c}\text { Pilot } \\
\text { construction } \\
\text { stage }\end{array}$ & $\begin{array}{l}\text { System } \\
\text { construction } \\
\text { stage }\end{array}$ & $\begin{array}{c}\text { Comprehensive } \\
\text { construction } \\
\text { stage }\end{array}$ \\
\hline
\end{tabular}

Fig. 1 The FIVE AND THREE SYSTEM Construction Process

The FIVE AND THREE SYSTEM construction promotes the human, financial, material and resource intensive control, integrates five core business including the power grid planning, construction, operation, maintenance and marketing, creates an internal control mode in which business operation system, supporting system, online monitoring system effectively match, strengthens the professional management, realizes centralized and efficient management, intensive resource sharing, integrated business, flat organization, smooth workflow, unified system standards, integrated and powerful security, provide institutional mechanisms with protect and support for the sustainable development of enterprises and the responsibility to perform. 


\section{State Grid Five and Three System Theoretical Connotation and Practice}

The FIVE AND THREE SYSTEM is a significant management change in State Grid, which is in accordance with the intensive, flat and professional development direction, change the organizational structure, innovative management model, optimize business processes, build a new power grid enterprise management system with Chinese characteristics.Its core components include: First, "Three Intensification" management system, which refers to the unified standard, system, procedure and organization system established with the aim of intensive management of human resources, capital, and material, implementing centralized management, uniting operation, optimizing allocation, playing scale and synergies of human resources, capital, and material, forming an intensive management model to adapt to the modern power grid enterprise developing requirement, improving the quality and efficiency of enterprise development. Second, "Five Big" business operating system, refers to the large planning system, large construction system, large operating system, large overhaul system, large marketing system build centering five core business of State Grid, to achieve centralized management and professional operation of the power grid business, significantly enhancing the Group's core business management and control capabilities. Third, supporting system, including a unified system, a unified standard system, a unified corporate culture, a unified information platform and a sound security system, providing the most basic institutional basis, material security and lasting power for the FIVE AND THREE SYSTEM.

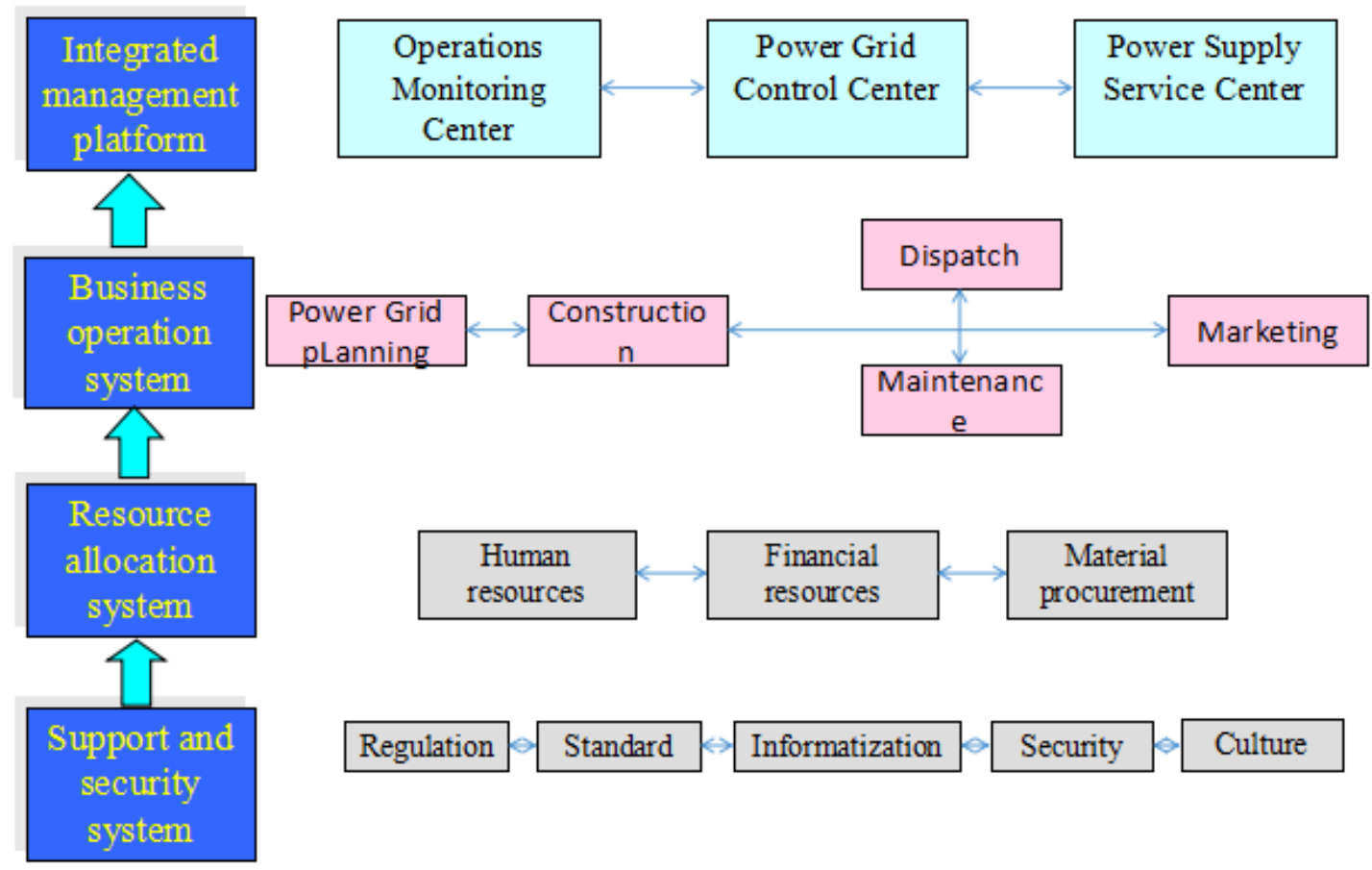

Fig. 2 The FIVE AND THREE SYSTEM New Power Grid Organization

In essence, the FIVE AND THREE SYSTEM construction is to deepen and promote group building towards the basic characteristics of group operation, from the strategic co-ordination, restructuring, process and mechanism, resource control four aspects. Among them, strategic co-ordination is a precursor to promote the member companies divide the work and coordinate around the overall strategy to lay the foundation for strategic coordination; Structure reorganization is a security to promote organizational structure flat, business management modular, responsibility system clear, to establish a scientific management system; Process and mechanism construction is a support, by optimizing the work process, building business collaboration mechanism, to achieve efficient operation; Resource intensive management is a grip, implementing intensive management of key resources to enhance the Group's overall allocation capacity of resources ,to achieve optimization and rational use of key resources and enhance economic efficiency. 


\section{State Grid Five and Three System Construction Revelation}

State Grid FIVE AND THREE SYSTEM Construction is a power grid management system reform implement from outside to inside under the national power system reform background. It promotes State Grid's modern enterprise management system construction and adapt to the power system monitoring requirements. FIVE AND THREE SYSTEM Construction not only perfects a set of enterprise management system in the modern enterprise system, but also solves some deep-seated problems existing in the modern enterprise system reform. It changes traditional production and operation model, effectively played the group synergies, improves Group's organizational capacity and vitality, push development mode change and brings a new stage for power grid enterprises modern corporate construction.By analyzing specific practices of State Grid FIVE AND THREE SYSTEM, we summarize the following four experiences of promoting large-scale state-owned enterprises to operate as a group:

First, by centralized management, normative system and optimized business process and other methods, consolidate and optimize deploying systematic human resources, capital and materials , reverse the "Perfunctorily United" management situation. Inside the FIVE AND THREE SYSTEM, in terms of talents, human resources overall management is implemented, which effectively integrates enterprise human resources and plays talents' intensive and use efficiency; in terms of finance, unified system and centralized management are implemented, which promotes high collaboration between finance and business, improves financial capacity to serve corporate development and prevent operating risk; in terms of material, centralized procurement scope are continuously expanded, centralized and unified, lean and efficient group procurement platform is constructed and material standardization is fully implemented to provide strong material security for five business and corporate operating. "Three Intensification", as an important part of the FIVE AND THREE SYSTEM, provides important security for power grid core business's production and operation, plays an important grip role in changing the long-term decentralized management. Human resources, capital and material are key resources for organizational operation, therefore grasping the intensive management of key resources can reverse the "Perfunctorily United" management situation.

Second, seize the corporate core value chain business links, construct modular management and control system, enhance Group's business organizational skills.Core business value chains are the main source of enterprise value creation, and the competitive advantage of an enterprise is also often determined by these strategic business value chains. The core of the FIVE AND THREE SYSTEM is to redefine organization business around planning, construction, operation, maintenance and marketing five businesses, adjust the organizational structure, construct interconnected business subsystems according to certain rules, give business content, management systems and methods to each business subsystem and forms a vertical-through modular business management and control system. Modular business control system has a unique advantage, it can quickly integrate their own resources according to the business module, make enterprises focus on building business capacity to enhance their core competitiveness, realizes transforming the core competitiveness of enterprises into a relatively independent business area and forms enterprise unique ability gene.

Third, adhere to flat development direction, compresses the vertical management level, enhance the group operation level.An important direction of the FIVE AND THREE SYSTEM is flat development, which requires to cancel legal representative levels of regional companies, provincial companies ,city-level companies and county-level companies, streamline the organization, reduce the long-term problems of numerous management levels, long chains and the resulting low efficiency of core resource allocation, significantly enhance the core business management and control capabilities and execution and promote intensive management. Flat has a strong advantage in the modern management: First, information can transfer quickly and reduce the possibility of distortion; Second, the ability of enterprises to adapt to market changes is greatly improved; Third, scientific level of decision is improved; Fourth, management expenses can be saved. By the FIVE AND THREE SYSTEM construction, the long-term problems of numerous management levels, 
long chains and the resulting low efficiency of core resource allocation can be reduced.

Fourth, optimize the adjustment of business functions interface, improve the horizontal coordination mechanism, strengthen the collaboration, accessibility, cooperation among all businesses and levels. Enterprise capabilities are embedded in the core processes. A good organizational system requires a scientific process to ensure efficient operation. Efficient business process is the core competitiveness of world-class enterprises, and reengineering process is also an important way for enterprises to improve the organizational operating efficiency and management capacity. To resolve existing organizational conflicts, promote horizontal synergy, develop core competitiveness, based on the comparative advantages of each link in the value chain, State Grid builds an enterprise process system with comprehensive coverage, strict duty and responsibility, settled time and standard, promoting the co-operation of the system modules, getting significant improvements in key indicators such as efficiency, quality, service and speed and creating value. Also, State Grid focuses on optimizing the adjustment function interface, improves the horizontal coordination mechanism, breaks communication barriers between departments, professionals and levels, strengthens co-ordination, standardize working procedures, improve working efficiency and make Group to achieve the operation like "a game of chess".

\section{References}

[1] Jiaxu Cheng, Yunfeng Li, The Theoretical Connotation and Strategic Significance of the FIVE AND THREE SYSTEM, J. State Grid. 02(2012) 78-79.

[2] Zhenya Liu, Exploration and Practice on the Management Reform of the FIVE AND THREE SYSTEM of State Grid Corporation of China. China Electric Power Press, 2015.

[3] Jingbo Xie, The Influence of the FIVE AND THREE SYSTEM on the Management Reform of Power Supply Enterprises, J. Enterprise Reform and Management. 18(2015).

[4] Jiankun Zhang, Strive to promote the TWO CHANGES, Comprehensive construct the FIVE AND THREE SYSTEM, J. State Grid. 01(2014). 